\title{
Effect of vildagliptin on hsCRP and arterial stiffness in patients with type 2 diabetes mellitus
}

\author{
loanna Zografou, ${ }^{1}$ Christos Sampanis, ${ }^{1}$ Eugenia Gkaliagkousi, ${ }^{1}$ Fotios Iliadis, ${ }^{2}$ \\ Athanasios Papageorgiou, ${ }^{1}$ Panagiotis Doukelis, ${ }^{3}$ Konstantinos Vogiatzis, ${ }^{1}$ Stella Douma ${ }^{1}$ \\ ${ }^{1} 2^{\text {nd }}$ Propedeutic Department of Internal Medicine, Hippokration Hospital of Thessaloniki; ${ }^{2}{ }^{\text {st }}$ Propedeutic Department \\ of Internal Medicine, AHEPA Hospital of Thessaloniki, Aristotle University of Thessaloniki; Greece; ${ }^{3}$ Department of \\ Internal Medicine, Western General Hospital, Edinburgh, UK
}

\begin{abstract}
OBJECTIVE: To evaluate the effect of dipeptidyl-peptidase-4 (DPP-4) inhibitor vildagliptin on high sensitivity C-reactive protein (hsCRP) and arterial stiffness (AS) in patients with type 2 diabetes (T2DM). DESIGN: Sixty-four drug-naive diabetic patients, with inadequate glycemic control, participated in this randomized, open-label study. Half of the patients received metformin $1700 \mathrm{mg} / \mathrm{d}$ and the other half of them received metformin $1700 \mathrm{mg} / \mathrm{d}$ plus vildagliptin $100 \mathrm{mg} / \mathrm{d}$. AS was measured by carotid-femoral Pulse Wave Velocity (cfPWV). Body weight (BW), body mass index (BMI), blood pressure (BP), hsCRP, glycosylated hemoglobin (HbA1c), fasting plasma glucose (FPG), lipid profile, albumin/creatinine ratio (ACR), fasting insulin, C-peptide, homeostasis model assessment of insulin resistance (HOMA-IR) and homeostasis model assessment of $\beta$-cell function (HOMA- $\beta$ ) were also assessed at baseline and after 6 months. RESULTS: Vildagliptin in combination with metformin had a beneficial influence on hsCRP, HbA1c, C-peptide and HOMA- $\beta$ index $(p<0.05)$ but had no effect on cfPWV, BP, BW, BMI, lipid profile, ACR and HOMA-IR compared with metformin alone ( $p=N S$ ). CONCLUSIONS: We have found that the addition of vildagliptin to metformin for a period of six months decreased hsCRP, improved glycemic control and $\beta$-cell function but had no effect on AS in drug-naive patients with T2DM.
\end{abstract}

Key words: Arterial stiffness, Dipeptidyl-peptidase-4 inhibitor, High sensitivity C-reactive protein, Pulse wave velocity, Vildagliptin

\section{INTRODUCTION}

Diabetes mellitus is a chronic disease associated

Address for correspondence:

Ioanna Zografou, MD, Second Propedeutic Department of Internal Medicine, Hippokration Hospital, 49 Konstantinoupoleos Str., 54642, Thessaloniki, Greece, Tel.: +302310892631, E-mail: Ioannazo@yahoo.gr

Received 21-01-2014, Accepted 19-03-2014 with a two- to fourfold increased risk of cardiovascular disease (CVD) ${ }^{1,2}$ Although antihyperglycemic drugs improve glycemic control the UKPDS (United Kingdom Prospective Diabetes Study) has found that metformin may confer cardiovascular benefits to certain subgroups of patients while the PROactive study (PROspective pioglitazone Clinical Trial In macroVascular Events) found similar beneficial 
effects of pioglitazone. ${ }^{3,4}$ However, there is still not sufficient evidence that antidiabetic therapies reduce the cardiovascular risk of patients with diabetes.

Incretin-based therapy has been approved for the treatment of type 2 diabetes mellitus (T2DM). Incretins are a group of gastrointestinal hormones, among which the glucagon-like peptide 1 (GLP-1) and the glucosedependent insulinotropic peptide (GIP), which are released in response to food ingestion, stimulating insulin secretion. This action, however, is limited by their rapid inactivation by the enzyme dipeptidyl peptidase-4 (DPP-4). ${ }^{5,6}$ Moreover, incretin hormones suppress glucagon secretion and seem to have some beneficial effect on $\beta$-cells function in experimental models. ${ }^{7}$ DPP-4 inhibitors reduce the breakdown of GLP-1 and improve glycemic control by increasing insulin secretion. ${ }^{8}$

Beyond its favorable action on metabolic control, GLP-1 seems to exert beneficial cardiovascular effects, while it also has vasodilatory properties thought to be partially mediated through a specific GLP-1 receptor on the vascular endothelium. Administration of inherent GLP-1 caused dilation of the aorta wall in animals. ${ }^{9}$ Probably some of the effects of GLP-1 are mediated through its metabolites and are independent of the GLP-1 receptor, acting instead through an NO/ cGMP-dependent mechanism. ${ }^{10}$

Vildagliptin is an oral agent that selectively inhibits DPP-4, increases levels of active GLP-1 and GIP and improves glycemic control in patients with T2DM. ${ }^{11}$ Moreover, vildagliptin decreases adipocytokines related to inflammation ${ }^{12}$ and inhibits monocyte activation/ chemotaxis. ${ }^{13}$ Recent studies have investigated the anti-inflammatory and antiatherosclerotic properties of DPP-4 inhibition and also the improvement in endothelium-dependent vasodilatation in subjects with T2DM, suggesting that this class of drugs might have favourable cardiovascular implications. ${ }^{14}$

Arterial stiffness (AS) is a strong predictor of cardiovascular morbidity and all-cause mortality in different populations and it is an independent predictor of 10-year mortality in patients with diabetes. ${ }^{15-17}$ High sensitivity CRP (hsCRP) as a marker of inflammation is reported to be independently related to an increased AS. ${ }^{18}$ The relationship between the presence of systemic inflammation and increased aortic stiff- ness has been documented in many studies involving both acute and chronic inflammation. ${ }^{19,20}$

Based on previous observations, we hypothesized that treatment with vildagliptin might beneficially affect inflammation and AS in patients with T2DM. We measured carotid-femoral pulse wave velocity (cfPWV), which is considered to be the most appropriate and accurate non-invasive method to quantify AS. Furthermore, this method is simple and reproducible and has been demonstrated to be a reliable predictor of cardiovascular mortality in different populations. ${ }^{21,22}$ Although vascular function has been studied in patients with diabetes, data concerning the effect of vildagliptin on hsCRP and AS are still lacking. The aim of this study was to investigate if 6 months treatment with vildagliptin would affect hsCRP and AS in drug-naive patients with T2DM.

\section{PARTICIPANTS AND METHODS}

Sixty-four drug-naive diabetic patients, aged $54.4 \pm 10.9$ years (mean $\pm \mathrm{SD}$ ) (38 men, 26 women), were recruited from our outpatient diabetic clinic in this prospective, open-label, randomized study. All participants were Caucasians. Inclusion criteria were 1) patients $\geq 18$ and $\leq 70$ years old and 2 ) inadequate glycemic control [glycosylated hemoglobin (HbA1c) 7-9\%] despite diet and exercise for 3 months. Patients with any macrovascular or microvascular diabetic complications, history of heart disease, uncontrolled hypertension [systolic Blood Pressure (BP) $\geq 180$ $\mathrm{mmHg}$ and/or diastolic $\mathrm{BP} \geq 110 \mathrm{mmHg}$ ], excessive dyslipidemia [total cholesterol (TC) $\geq 350 \mathrm{mg} / \mathrm{dl}$, triglycerides (TG) $\geq 400 \mathrm{mg} / \mathrm{d}$ ], elevated liver enzymes three times above the upper normal range and any other comorbidity that could interfere with the study were excluded. Pregnant women or those who were breastfeeding or planning for pregnancy were also not eligible. Women of childbearing age were advised to use contraception if they were sexually active.

The study was approved by the local Ethics Committee (Ethics Committee of Aristotle University of Thessaloniki) and conducted in accordance with the Helsinki Declaration. Informed consent was obtained from every participant.

Enrolled patients were assigned randomly either to receive metformin ( $850 \mathrm{mg}$ twice daily) or to receive 
metformin ( $850 \mathrm{mg}$ twice daily) plus vildagliptin (50 $\mathrm{mg}$ twice daily) for 6 months. Also, the antihypertensive and lipid-lowering drugs were unchanged during the study period. Patients in both groups were instructed to strictly maintain dietary habits and daily activities during the course of the study.

Participants were assessed at the outpatient clinic two times: at baseline and at 6 months. Blood samples for biochemical measurements were collected and cfPWV was measured at baseline and at the end of the study.

Adverse events were monitored throughout the study. Hypoglycemia was defined as capillary blood result $<70 \mathrm{mg} / \mathrm{dl}$ and/or signs or symptoms of hypoglycemia resolving after carbohydrate intake.

CfPWV was measured by the SphygmoCor system by sequential recording electrocardiogram-gated carotid femoral waveforms. The same investigator performed all measurements. The patients were informed not to take any medicine on the morning of their visit and smokers also not to smoke. BP was measured at the brachial artery using a semiautomatic device (Omron digital tonometer) after $10 \mathrm{~min}$ rest in the seated position. CfPWV was performed in a quiet, well ventilated room after 10 min resting in the supine position. The distance from the lowest point of the sternal notch to the carotid and femoral artery sites was obtained. Waveforms were captured from the carotid and femoral arteries using the tonometer connected to the SphygmoCor device. Waveforms were gated by the $\mathrm{R}$ wave on the simultaneously recorded electrocardiogram and PWV was measured after at least 15 sequential waveforms. The average of three recordings of cfPWV was used in the analysis.

Body weight (BW) was measured with light clothing on a balance scale and height to the nearest 0.5 $\mathrm{cm}$ using a meter that was stabilized on the wall. BMI was calculated as weight (kilograms) divided by height (meters) squared. Percentage fat mass was measured by body fat analyzer (Tanita TBF-531 body fat scale). Waist circumference was measured at minimal respiration by a flexible tape parallel to the floor and immediately above the iliac crest.

All laboratory tests were performed after a $12 \mathrm{~h}$ overnight fast. Biochemistry, including glucose, lipid levels (TC; high density lipoprotein cholesterol, HDL$\mathrm{C}$; and TG) liver enzymes (alanine transaminase, ALT; aspartate transaminase, AST) and creatinine, were evaluated on an Olympus analyzer (Olympus Diagnostica GmbH, Clare, Ireland). Low-density lipoprotein cholesterol (LDL-C) was calculated using Friedewald's formula. ${ }^{23} \mathrm{HbA} 1 \mathrm{c}$ and albumin/creatinine ratio (ACR) were measured by an automated latex immunoagglutination inhibition assay (DCA 2000, Bayer Diagnostics Europe Ltd., Dublin, Ireland). Estimated glomerular filtration rate (eGFR) was calculated according to the Gault-Cockroft equation (eGFR $\left(\mathrm{ml} / \mathrm{min} / 1.73 \mathrm{~m}^{2}\right)=[(140$-Age $) \times \mathrm{BW}($ in $\mathrm{kg})] \backslash[72$ $\times$ Serum creatinine $($ in $\mathrm{mg} / \mathrm{dL})] \times(0.85$ if female $)$.

HsCRP was quantitated by an immunoassay (Quantikine Human C - reactive Protein Immunoassay, R\&D Systems Europe Ltd, UK) (normal range, $0.1-4.3 \mathrm{mg} / \mathrm{L}$ ). Inter-assay and intra-assay coefficients of variation for hs-CRP averaged $6 \%$ and $4.4 \%$, respectively. Insulin was quantitated by an immunoradiometric assay (INS-IRMA, DIAsourceImmunoAssays S.A., Louvain-la-Neuve, Belgium) (normal range, 2.6-24.9 $\mu \mathrm{U} / \mathrm{ml}$ ). Inter-assay and intra-assay coefficients of variation for insulin averaged $6.5 \%$ and $2.1 \%$, respectively. C-peptide was quantitated by a radioimmunoassay (C-PEP RIA-CT, DIAsourceImmunoAssays S.A., Louvain-la-Neuve, Belgium) (normal range 0.51-2.72 ng/ml). Inter-assay and intra-assay coefficients of variation averaged $11.8 \%$ and $5.6 \%$, respectively. Insulin resistance was estimated by homeostasis model assessment of insulin resistance, HOMA-IR [FBG $(\mathrm{mmol} / \mathrm{L}) \mathrm{x}$ fasting insulin $(\mu \mathrm{U} / \mathrm{ml}) / 22.5$ ] and $\beta$-cell function was assessed by homeostasis model assessment of $\beta$-cell function, HOMA- $\beta[20 \times$ fasting insulin $(\mu \mathrm{U} / \mathrm{ml}) /$ FBG (mmol/L) - 3.5]. ${ }^{24}$

\section{STATISTICAL ANALYSIS}

All data were analyzed using the statistical package SPSS (version 17; SPSS Inc., Chicago, Illinois, USA). Normality of distribution was assessed by the Kolmogorov-Smirnov test. Continuous data are presented as mean $\pm 1 \mathrm{SD}$ and categorical data as absolute numbers and percentages. Comparisons within groups were performed by the paired $t$ test and Wilcoxon Signed rank test and between groups 
by the independent $t$ test and Mann-Whitney $U$ test for normal and non-normal distributions, respectively. The Chi-square test was used for comparisons of categorical variables between groups. Pearson's and Spearman's correlation coefficients were used to detect dependence between normally and nonnormally distributed variables, respectively. In all cases, a 2-tailed $\mathrm{p}$ value less than 0.05 was considered statistically significant.

\section{RESULTS}

Sixty-four patients ( 38 men and 26 women) participated in the study. Baseline characteristics are presented in Table 1. No significant differences were observed between groups at baseline.

All results are summarized in Table 2. The combination of vildagliptin with metformin was associated with a significant decrease in hsCRP compared with metformin alone (vildagliptin plus metformin group at baseline $3.4 \pm 2.8 \mathrm{mg} / \mathrm{L}, \Delta$ at 6 months $-0.4 \pm 2.8$ $\mathrm{mg} / \mathrm{L}, \mathrm{p}<0.05$, metformin group $2.5 \pm 2.3 \mathrm{mg} / \mathrm{L}, \Delta$ at 6 months $1.1 \pm 1.6 \mathrm{mg} / \mathrm{L}, \mathrm{p}<0.05$ between groups). In addition, $\mathrm{HbA} 1 \mathrm{c}$ was decreased more effectively in the same group $(\mathrm{p}<0.05$ for difference within groups and between groups) and HOMA- $\beta$ and C-peptide were also beneficially affected $(p<0.05$ for difference within vildagliptin plus metformin group and between groups). There was no correlation between the hsCRP reduction and the HbA1c, HOMA- $\beta$ and $\mathrm{C}$-peptide improvement in the vildagliptin plus metformin group $(\mathrm{p}=\mathrm{NS})$. No effect was found on cfPWV (no statistical difference within groups and between groups: cfPWV vildagliptin plus metformin group at baseline $8.6 \pm 2.1 \mathrm{~m} / \mathrm{sec}, \Delta$ at 6 months $-0.3 \pm 1.5$ $\mathrm{m} / \mathrm{sec}, \mathrm{p}=\mathrm{NS}$, metformin group $8.9 \pm 2 \mathrm{~m} / \mathrm{sec}, \Delta$ at 6 months $0.2 \pm 1.8 \mathrm{~m} / \mathrm{sec}, \mathrm{p}=\mathrm{NS})$. BW, BMI, HOMA-IR and fat mass percentage were reduced in both groups $(\mathrm{p}<0.05$ for difference within groups), but without difference between groups. There was no statistically significant difference in lipid profile, BP, eGFR and fasting insulin within and between groups. Although vildagliptin reduced ACR ( $<<0.05$ for difference within group), the difference between groups was not significant. There was a significant reduction in liver enzymes in the metformin group but with no difference between groups at the end of study.
Table 1. Baseline characteristics

\begin{tabular}{|c|c|c|}
\hline & $\begin{array}{c}\text { Vildagliptin } \\
+ \\
\text { Metformin group } \\
\end{array}$ & $\begin{array}{l}\text { Metformin } \\
\text { group }\end{array}$ \\
\hline Number (men/women) & $18 / 14$ & $20 / 12$ \\
\hline Age (years) & $52 \pm 11.2$ & $56 \pm 10.5$ \\
\hline BMI $\left(\mathrm{kg} / \mathrm{m}^{2}\right)$ & $31.6 \pm 4.6$ & $32.2 \pm 5.9$ \\
\hline Weight (kg) & $90.1 \pm 14.3$ & $93.9 \pm 20.7$ \\
\hline Waist (cm) & $106.5 \pm 9.5$ & $112.4 \pm 13.8$ \\
\hline $\operatorname{cfPWV}(\mathrm{m} / \mathrm{sec})$ & $8.6 \pm 2.1$ & $8.9 \pm 2$ \\
\hline hs-CRP (mg/L) & $3.4 \pm 2.8$ & $2.5 \pm 2.3$ \\
\hline $\operatorname{HbA1c}(\%)$ & $8.1 \pm 0.8$ & $8 \pm 0.8$ \\
\hline $\mathrm{FPG}(\mathrm{mg} / \mathrm{dl})$ & $145.5 \pm 39.4$ & $142.3 \pm 27.5$ \\
\hline Cholesterol (mg/dl) & $187.3 \pm 35$ & $195.7 \pm 51.1$ \\
\hline $\mathrm{HDL}(\mathrm{mg} / \mathrm{dl})$ & $47.1 \pm 10.2$ & $45.7 \pm 10$ \\
\hline LDL (mg/dl) & $103.3 \pm 30.7$ & $114.7 \pm 42.5$ \\
\hline Triglycerides (mg/dl) & $178.5 \pm 81.9$ & $176.8 \pm 65$ \\
\hline Creatinine (mg/dl) & $0.93 \pm 0.17$ & $0.93 \pm 0.19$ \\
\hline $\mathrm{eGFR}\left(\mathrm{ml} / \mathrm{min} / 1.73 \mathrm{~m}^{2}\right)$ & $122.0 \pm 30.2$ & $123.1 \pm 35.2$ \\
\hline SGOT (U/L) & $24.0 \pm 10.5$ & $23.7 \pm 8.3$ \\
\hline SGPT (U/L) & $31.77 \pm 18.9$ & $30.7 \pm 16.2$ \\
\hline Systolic BP (mmHg) & $134.5 \pm 16.1$ & $131.1 \pm 2$ \\
\hline Diastolic BP (mmHg) & $82.1 \pm 11.7$ & $79.2 \pm 10.8$ \\
\hline Insulin $(\mu \mathrm{U} / \mathrm{ml})$ & $9.5 \pm 7.2$ & $8 . \pm 3.9$ \\
\hline C-peptide (ng/ml) & $3.8 \pm 1.6$ & $4.3 \pm 1.6$ \\
\hline HOMA- $\beta$ & $46.4 \pm 28.9$ & $49.7 \pm 50.1$ \\
\hline HOMA-IR & $3.7 \pm 3.9$ & $3 \pm 1.7$ \\
\hline Fat mass $(\%)$ & $35.1 \pm 9.4$ & $35.6 \pm 9.9$ \\
\hline $\mathrm{ACR}(\mathrm{mg} / \mathrm{g})$ & $26.2 \pm 40.1$ & $18.4 \pm 19.3$ \\
\hline Smoking $(\%)$ & 12.5 & 25 \\
\hline Antihypertensive drugs (\%) & 40.6 & 43.8 \\
\hline Statin $(\%)$ & 40.6 & 53.1 \\
\hline
\end{tabular}

Data are means \pm SD. BMI: body mass index; BP: blood pressure; FPG: fasting plasma glucose; HbAlc: glycosylated hemoglobin; HDL: high-density lipoprotein; LDL: low-density lipoprotein; eGFR: estimated glomerular filtration rate; HOMA- $\beta$ : homeostasis model assessment of $\beta$-cell function; HOMA-IR: reciprocal index of homeostasis model assessment; cfPWV: carotid femoral pulse wave velocity; ACR: Albumin/Creatinine ratio.

No significant differences were observed between the groups at baseline $(\mathrm{p}=\mathrm{NS})$.

No serious adverse event was reported. One case of urinary tract infection and one case of upper respiratory tract infection was observed in the metformin group. In the vildagliptin plus metformin group there was one case of nasopharyngitis. 
Table 2. Changes of clinical and biochemical variables in the Metformin group and Vildagliptin+Metformin group

\begin{tabular}{|c|c|c|c|c|c|c|c|}
\hline \multirow[t]{2}{*}{ Parameter } & \multicolumn{3}{|c|}{ Vildagliptin+Metformin group } & \multicolumn{3}{|c|}{ Metformin group } & \multirow[b]{2}{*}{$\mathbf{P 2}$} \\
\hline & Baseline & $\Delta$ at 6 months & P1 & Baseline & $\Delta$ at 6 months & P1 & \\
\hline BMI $\left(\mathrm{kg} / \mathrm{m}^{2}\right)$ & $31.6 \pm 4.6$ & $-0.4 \pm 0.9$ & 0.011 & $32.4 \pm 5.8$ & $-0.6 \pm 1.3$ & 0.023 & NS \\
\hline Weight (kg) & $90.1 \pm 14.3$ & $-1.2 \pm 2.6$ & 0.011 & $93.9 \pm 20.7$ & $-1.6 \pm 3.8$ & 0.021 & NS \\
\hline Waist (cm) & $106.5 \pm 9.5$ & $-0.3 \pm 1.5$ & 0.030 & $112.4 \pm 13.9$ & $-0.2 \pm 1.8$ & 0.001 & NS \\
\hline $\operatorname{cfPWV}(\mathrm{m} / \mathrm{sec})$ & $8.6 \pm 2.1$ & $-0.3 \pm 1.5$ & NS & $8.9 \pm 2$ & $0.2 \pm 1.8$ & NS & NS \\
\hline hs-CRP (mg/L) & $3.4 \pm 2.8$ & $-0.4 \pm 2.8$ & 0.040 & $2.5 \pm 2.3$ & $1.1 \pm 1.6$ & NS & 0.032 \\
\hline HbAlc $(\%)$ & $8.1 \pm 0.8$ & $-1.7 \pm 0.7$ & $<0.001$ & $8 \pm 0.8$ & $-1.2 \pm 1.2$ & $<0.001$ & 0.048 \\
\hline $\mathrm{FPG}(\mathrm{mg} / \mathrm{dl})$ & $145.5 \pm 39.4$ & $-33.2 \pm 34.3$ & $<0.001$ & $142.3 \pm 27.5$ & $-17.5 \pm 35.3$ & 0.010 & 0.050 \\
\hline Cholesterol (mg/dl) & $187.3 \pm 35$ & $-8.2 \pm 39.5$ & NS & $195.7 \pm 51.1$ & $-12.2 \pm 44$ & NS & $\mathrm{NS}$ \\
\hline HDL (mg/dl) & $47.1 \pm 10.2$ & $1.3 \pm 8.1$ & NS & $45.7 \pm 10$ & $3.1 \pm 7.8$ & 0.034 & NS \\
\hline $\mathrm{LDL}(\mathrm{mg} / \mathrm{dl})$ & $103.3 \pm 30.7$ & $-3.2 \pm 31.6$ & NS & $114.7 \pm 42.5$ & $-11.6 \pm 34.7$ & NS & NS \\
\hline Triglycerides (mg/dl) & $178.5 \pm 81.9$ & $-18.6 \pm 67.2$ & NS & $176.8 \pm 64.9$ & $-24.4 \pm 70$ & NS & NS \\
\hline Creatinine $(\mathrm{mg} / \mathrm{dl})$ & $0.93 \pm 0.17$ & $0.01 \pm 0.13$ & NS & $0.93 \pm 0.19$ & $-0.01 \pm 0.10$ & NS & NS \\
\hline $\mathrm{eGFR}\left(\mathrm{ml} / \mathrm{min} / 1.73 \mathrm{~m}^{2}\right)$ & $122.0 \pm 30.2$ & $0.4 \pm 22.6$ & NS & $123.1 \pm 35.2$ & $2.9 \pm 11.5$ & NS & NS \\
\hline SGOT (U/L) & $24.0 \pm 10.5$ & $-2.0 \pm 9.8$ & NS & $23.7 \pm 8.3$ & $-3.5 \pm 4.9$ & 0.001 & NS \\
\hline SGPT (U/L) & $31.77 \pm 18.9$ & $-4.5 \pm 17.2$ & NS & $30.7 \pm 16.2$ & $-5.2 \pm 8.5$ & 0.002 & NS \\
\hline Systolic BP (mmHg) & $134.5 \pm 16.1$ & $-3.9 \pm 15.4$ & NS & $131.1 \pm 2$ & $-2.1 \pm 21$ & NS & NS \\
\hline Diastolic BP (mmHg) & $82.1 \pm 11.7$ & $0.9 \pm 11.6$ & NS & $79.2 \pm 10.8$ & $2.2 \pm 13.2$ & NS & NS \\
\hline Insulin $(\mu \mathrm{IU} / \mathrm{ml})$ & $9.5 \pm 7.2$ & $1.5 \pm 5.7$ & NS & $8.7 \pm 4.4$ & $0.7 \pm 3.7$ & NS & NS \\
\hline C-peptide (ng/ml) & $3.8 \pm 1.6$ & $1.3 \pm 3.6$ & 0.048 & $4.3 \pm 1.6$ & $-0.3 \pm 1.5$ & NS & 0.025 \\
\hline HOMA- $\beta$ & $46.4 \pm 28.8$ & $22 \pm 33.8$ & 0.001 & $49.7 \pm 50.1$ & $8.1 \pm 55.8$ & NS & 0.018 \\
\hline HOMA-IR & $3.7 \pm 3.93$ & $-1.5 \pm 3.42$ & 0.025 & $3 \pm 1.7$ & $-0.6 \pm 1.6$ & 0.044 & NS \\
\hline Fat mass $(\%)$ & $35.1 \pm 9.4$ & $-1 \pm 2.2$ & $<0.001$ & $35.7 \pm 9.9$ & $-1.6 \pm 3.6$ & 0.017 & NS \\
\hline $\mathrm{ACR}(\mathrm{mg} / \mathrm{g})$ & $26.2 \pm 40.1$ & $-5.6 \pm 31.6$ & 0.002 & $18.4 \pm 19.3$ & $3.4 \pm 25.8$ & NS & NS \\
\hline
\end{tabular}

Data are means \pm SD. $\Delta$ : difference at 6 months; BMI: body mass index; BP: blood pressure; FPG: fasting plasma glucose; HbA1c: glycosylated hemoglobin; HDL: high-density lipoprotein; LDL: low-density lipoprotein; eGFR: estimated glomerular filtration rate; HOMA- $\beta$ : homeostasis model assessment of $\beta$-cell function; HOMA-IR: reciprocal index of homeostasis model assessment; cfPWV: carotid femoral pulse wave velocity; ACR: Albumin/Creatinine ratio; NS: not significant; P: P1 value of difference within groups; P2 value of difference between the groups.

\section{DISCUSSION}

In our study, the addition of vildagliptin to metformin decreased hsCRP independently of glycemic control but it had no effect on AS in drug-naive patients with T2DM after 6 months.

Cardiovascular disease is the leading cause of death in patients with diabetes due to premature atherosclerosis and arterial complications. Inflammatory mediators, such as hsCRP or IL-6 are increased in diabetes ${ }^{18}$ and inflammation seems to play a key role in the pathogenesis of vascular dysfunction. ${ }^{25} \mathrm{In}$ addition, hyperglycemia promotes the formation of advanced glycation end-products and the glycation of proteins resulting in changes in elastin and inelastic matrix materials located in the vessel wall and finally their stiffening. ${ }^{26}$

Vascular function has been investigated in patients with T2DM and it has been shown that these patients have increased AS, reduced aortic distensibility and impaired endothelial function, as this is estimated by the method of flow-mediated dilation, when compared to nondiabetic population matched for sex, age and serum total cholesterol. ${ }^{27,28}$

The assessment of inflammatory burden and vas- 
cular function in the early stage of diabetes might be of great prognostic importance. Previous studies have shown that AS is a strong predictor of cardiovascular morbidity and all-cause mortality in different populations and that it is an independent predictor of 10-year mortality in patients with diabetes. ${ }^{13,15,16}$ Among the different methods to assess AS, cfPWV is the most robust one. This method is useful not only for prediction of future cardiovascular events but also for risk stratification and probably for early therapeutic intervention in patients with diabetes. ${ }^{29}$

Besides glycemic control, new treatment strategies for diabetes have focused on the reduction of cardiovascular disease and its complications. There is a growing body of evidence coming from experimental and small clinical trials that GLP-1-mimetics therapies have antiatherosclerotic and antiremodeling properties beyond glycemic control. ${ }^{30,31}$ Apart from GLP-1, its degradation product, GLP-1 (9-37), was found to have beneficial effects on the cardiovascular system and vascular tone as well. ${ }^{32}$ It remains to be seen if GLP-1 increase by DPP-4 inhibition exhibits the same vascular profile.

Although two recently published studies have shown that vildagliptin improved endothelium-dependent vasodilatation in subjects with T2DM and blocked vascular injury of the thoracic aorta in diabetic rats, ${ }^{13,33}$ there is no sufficient data regarding the effect of vildagliptin on hsCRP and AS in patients with diabetes until now. ${ }^{34,35}$ We hypothesized that vildagliptin might reduce systemic inflammation and, as a consequence, improve AS. Previous studies have provided convincing evidence that there is a relationship between hsCRP levels and AS. ${ }^{36,37}$ However, this relationship was not confirmed in our study, as vildagliptin failed to improve cfPWV during the 6-month follow-up. This might be due to the short (6 months) duration of therapy which was inadequate to induce any beneficial structural changes in arterial walls. Furthermore, although vildagliptin improved the glycemic profile of the patients, it had no effect on parameters such as BP and BMI which greatly influence PWV. The lack of any amelioration in these factors may explain the absence of functional changes in the arterial walls that would result in improvement of arterial distensibility and thereby reduce PWV. It is also possible that a larger cohort of patients is needed in order to establish an independent correlation among hsCRP levels and AS.

Metformin was found to reduce cfPWV after 3 months in young women with polycystic ovary syndrome. However, these results are not comparable because these women did not have T2DM, were younger (mean age 31 ) and had lower baseline PWV. ${ }^{38}$ On the other hand, in another metformin study, in a non-diabetic African - American population with insulin resistance and treated with metformin for 24 months, a significant increase in PWV was observed when compared with placebo. ${ }^{39}$

Vildagliptin increased insulin secretion and improved $\beta$-cell function (improvement in $\mathrm{C}$-peptide and HOMA- $\beta$ index, $p<0.05$ ). The same effect of vildagliptin on glycemic control has been demonstrated in another study. ${ }^{40}$ There was no change in fasting insulin, HOMA-IR, lipid profile, BP and ACR. Several studies have evaluated the effects of GLP-1 based therapies on preservation of $\beta$-cell function. There is some evidence that vildagliptin treatment ameliorates $\beta$-cell dysfunction in patients with T2DM as well as impaired fasting glucose. This could offer an alternative approach in preventing the progression of diabetes. ${ }^{41,42}$

The addition of vildagliptin to metformin had no effect on BW, BMI, fat mass and FPG. The neutral effect of vildagliptin on BW and BMI is in agreement with previous studies and it can be explained by the fact that unlike mimetics, which boost GLP-1 activity this leading to BW changes, DPP-4 inhibition works by slowing incretins degradation, therefore the level of circulating GLP-1 in inhibition therapy is significantly lower than that of mimetics therapy. ${ }^{43}$

It should be noted here that there are several limitations in our study. The most important limitation is the small number of subjects. Also, it was open-label and perhaps the period of intervention was too short to affect AS. Thus, our results should be interpreted with caution and, undoubtedly, long-term placebocontrolled studies are needed.

In conclusion, we have found that the addition of vildagliptin to metformin given for a period of 6 months decreased hsCRP and improved glycemic control and $\beta$-cell function but had no effect on AS 
in drug-naive patients with T2DM. Further large randomized placebo controlled long-term studies are required to evaluate the effect of vildagliptin on inflammation and vascular function in patients with T2DM.

\section{FINANCIAL DISCLOSURES}

None declared.

\section{REFERENCES}

1. King H, Aubert RE, Herman WH, 1998 Global burden of diabetes, 1995-2005. Prevalence, numerical estimates, projections. Diabetes Care 21: 1414-1431.

2. Brand FN, Abbot RD, Kannel WB, 1989 Diabetes, intermittent claudication and risk of cardiovascular events. The Framingham study. Diabetes 38: 504-509.

3. UK Prospective Diabetes Study (UKPDS) Group, 1998 Effect of intensive blood-glucose control with metformin on complications in overweight patients with type 2 diabetes (UKPDS 34). Lancet 352: 854-865.

4. Holman R, Retnakaran R, Farmer A, Stevens R, 2006 PROactive study. Lancet 367: 25-26.

5. Kieffer TJ, Habener JF, 1999 The glucagon-like peptides. Endocr Rev 20: 876-913.

6. Kieffer TJ, McIntosh CH, Pederson RA, 1995 Degradation of glucose-dependent insulinotropic polypeptide and truncated glucagon-like peptide 1 in vitro and in vivo by dipeptidyl peptidase IV. Endocrinology 136: 3585-3596.

7. Mu J, Woods J, Zhou YP, 2006 Chronic inhibition of dipeptidyl peptidase-4 with a sitagliptin analog preserves pancreatic b-cell mass and function in a rodent model of type 2 diabetes. Diabetes 55: 1695-1704.

8. Ahrén B, 2008 Emerging dipeptidyl peptidase-4 inhibitors for the treatment of diabetes. Expert Opin Emerg Drugs 13: 593-607.

9. Nyström T, Gutniak MK, Zhang Q, et al, 2004 Effects of glucagon-like peptide- 1 on endothelial function in type 2 diabetes patients with stable coronary artery disease. Am J Physiol Endocrinol Metab 287: E1209-E1215.

10. Ban K, Noyan-Ashraf M, Hoefer J, Bolz SS, Drucker DJ, Husain M, 2008 Cardioprotective and vasodilatory actions of glucagon-like peptide 1 receptor are mediated through both glucagon-like peptide 1 receptordependent and -independent pathways. Circulation 117: 2340-2350.

11. Mari A, Sallas WM, He YL, et al, 2005 Vildagliptin, a dipeptidyl peptidase-IV inhibitor, improves modelassessed beta-cell function in patients with type 2 diabetes. J Clin Endocrinol Metab 90: 4888-4894.

12. Derosa G, Ragonesi PD, Carbone A, et al, 2012 Vildagliptin action on some adipocytokine levels in type 2 diabetic patients: a 12-month, placebo-controlled study. Expert Opin Pharmacother 13: 2581-2591.

13. Shah Z, Kampfrath T, Deiuliis JA, et al, 2011 Long-term dipeptidyl-peptidase 4 inhibition reduces atherosclerosis and inflammation via effects on monocyte recruitment and chemotaxis. Circulation 124: 2338-2349.

14. Van Poppel PC, Netea MG, Smits P, Tack CJ, 2011 Vildagliptin improves endothelium-dependent vasodilatation in type 2 diabetes. Diabetes Care 34: 2072-2077.

15. Boutouyrie P, Tropeano AI, Asmar R, et al, 2002 Aortic stiffness is an independent predictor of primary coronary events in hypertensive patients: a longitudinal study. Hypertension 39: 10-15.

16. Asmar R, Rudnichi A, Blacher J, London GM, Safar ME, 2001 Pulse pressure and aortic pulse wave are markers of cardiovascular risk in hypertensive populations. Am J Hypertens 14: 91-97.

17. Strandberg TE, Salomaa VV, Vanhanen HT, Pitkala K, Miettinen TA, 2002 Isolated diastolic hypertension, pulse pressure, and mean arterial pressure as predictors of mortality during a follow-up of up to 32 years. J Hypertens 20: 399-404.

18. Roman MJ, Deveraux RB, Schwartz JE, et al, 2005 Arterial stiffness in chronic inflammatory diseases. Hypertension 46: 194-199.

19. Vlachopoulos C, Dima I, Aznaouridis K, et al, 2005 Acute systemic inflammation increases arterial stiffness and decreases wave reflections in healthy individuals. Circulation 112: 2193-2200.

20. Maki-Pataja KM, Booth AD, Hall FC, et al, 2007 Ezetimibe and simvastatin reduce inflammation, disease activity, and aortic stiffness and improve endothelial function in rheumatoid arthritis. J Am Coll Cardiol 50: 852-858.

21. The Reference Values for Arterial Stiffness Collaboration, 2010 Determinants of pulse wave velocity in healthy people and in the presence of cardiovascular risk factors: 'establishing normal and reference values'. Eur Heart J 31: 2338-2350.

22. Mackenzie IS, Wilkinson IB, Cockroft J, 2002 Assessment of arterial stiffness in clinical practice. QJM 95: 67-74.

23. Friedewald WT, Levy RI, Fredrickson DS, 1972 Estimation of the concentration of low-density lipoprotein cholesterol in plasma, without use of the preparative ultracentrifuge. Clin Chem 18: 499-502.

24. Matthews DR, Hosker JP, Rudenski AS, Naylor BA, Treacher DF, Turner RC, 1985 Homeostasis model assessment: insulin resistance and b-cell function from fasting plasma glucose and insulin concentrations in man. Diabetologia 28: 412-419.

25. Pickup JC, Crook MA, 1998 Is type II diabetes mellitus a disease of the innate immune system ? Diabetologia 41: 1241-1248.

26. Tedesco MA, Natale F, Di Salvo G, Caputo S, Capasso M, Calabro R, 2004 Effects of coexisting hypertension 
and type II diabetes mellitus on arterial stiffness. J Hum Hypertens 18: 469-473.

27. Lee JM, Shirodaria C, Jackson CE, et al, 2007 Multimodal magnetic resonance imaging quantifies atherosclerosis and vascular dysfunction in patients with type 2 diabetes mellitus. Diab Vasc Dis Res 4: 44-48.

28. Van Der Meer RW, Diamant M, Westenberg JJ, et al, 2007 Magnetic resonance assessment of aortic pulse wave velocity, aortic distensibility, and cardiac function in uncomplicated type 2 diabetes mellitus. J Cardiovasc Magn Reson 9: 645-651.

29. Theilade S, Lajer M, Persson F, Joergensen C, Rossing P, 2013 Arterial stiffness is associated with cardiovascular, renal, retinal and autonomic disease in type 1 diabetes. Diabetes Care 36: 715-721.

30. Keating GM, 2010 Vildagliptin: a review of its use in type 2 diabetes mellitus. Drugs 70: 2089-2112.

31. Yin M, Silljé HH, Meissner M, Van Gilst WH, De Boer RA, 2011 Early and late effects of the DPP-4 inhibitor vildagliptin in rat model of post-myocardial infarction heart failure. Cardiovasc Diabetol 1186/1475-2840-1085.

32. Shah Z, Pineda C, Kampfrath T, et al, 2011 Acute DPP4 inhibition modulates vascular tone through GLP-1 independent pathways. Vascul Pharmacol 55: 2-9.

33. Matsui T, Nishino Y, Takeuchi M, Yamagishi S, 2011 Vildagliptin blocks vascular injury in thoracic aorta of diabetic rats by suppressing advanced glycation end product-receptor axis. Pharmacol Res 63: 383-388.

34. Derosa G, Maffiloi P, 2012 Dipeptidyl peptidase-4 inhibitors: 3 years of experience. Diabet Technol Ther 14: $350-364$.

35. Derosa G, Maffioli P, Ferrari I, et al, 2010 Effects of one year treatment of vildagliptin added to pioglitazone or glimepiride in poorly controlled type 2 diabetic patients.
Horm Metab Res 42: 663-669.

36. Yasmin, McEniery CM, Wallace S, Mackenzie IS, Cockroft JR, Wilkinson IB, 2004 C-reactive protein is associated with arterial stiffness in apparently healthy individuals. Arterioscler Thromb Vasc Biol 24: 969-974.

37. Kim JS, Kang TS, Kim JB, et al, 2007 Significant association of C-reactive protein with arterial stiffness in treated non-diabetic hypertensive patients. Atherosclerosis 192: 401-406.

38. Agarwal N, Rice SP, Bolusani H, et al, 2010 Metformin reduces arterial stiffness and improves endothelial function in young women with polycystic ovary syndrome: a randomized, placebo-controlled, crossover trial. J Clin Endocrinol Metab 95: 722-730.

39. Stakos DA, Schuster DP, Sparks EA, Wooley CF, Osei K, Boudoulas H, 2005 Long term cardiovascular effects of oral antidiabetic agents in non-diabetic patients with insulin resistance: double blind, prospective, randomised study. Heart 91: 589-594.

40. Bosi E, Camisasca RP, Collober C, Rochotte E, Garber AJ, 2007 Effects of vildagliptin on glucose control over 24 weekes in patients with type 2 diabetes inadequately controlled with metformin. Diabetes Care 30: 890-895.

41. Ahren B, Pacini G, Tura A, Folley JE, Schweizer A, 2007 Improved meal-related insulin processing contributes to the enhancement of B-cell function by the DPP-4 inhibitor vildagliptin in type 2 diabetes. Horm Metab Res 39: 826-829.

42. Utzschneider KM, Tong J, Montgomery B, 2008 The dipeptidyl peptidase-4 inhibitor vildagliptin improves beta-cell function and insulin sensitivity in subjects with impaired fasting glucose. Diabetes Care 31: 108-113.

43. Vilsbøll T, 2007 Liraglutide: an once-daily GLP-1 analogue for the treatment of type 2 diabetes mellitus. Expert Opin Investig Drugs 16: 231-237. 